\title{
HAVE THE ADOLESCENTS BE POWERFUL IN THE IMPLEMENTATION PROGRAM FOR THEM
}

\author{
Pulung Siswantara*, Oedojo Soedirham and Muthmainnah \\ Faculty of Public Health, University Airlangga, Indonesia
}

Email: pulung-s@fkm.unair.ac.id

\begin{abstract}
The population of adolescents in Indonesia is almost $30 \%$ of the total population of Indonesia. This figure is quite large as a potential asset for the country. Today the percentage of adolescents who engage in high-risk behavior is quite high. Data of Health Ministry that show the number of HIV cases in productive age is increasing from year to year. Therefore, youth health programs are a national priority. Many teenage health programs have been conducted from various sectors. This study aims to identify adolescent perceptions on the implementation of youth health programs. Teenagers, in this case, are grouped into 2, namely as a peer educator and as the target program (user). This study looked at adolescent perceptions in relation to the strategic steps of adolescent health programs. This research is descriptive research by using a qualitative method, subjects of research is adolescent stakeholder which is consisting of school's teenagers, adolescent community, mosque teenagers and street teenagers. Data were collected through interviews with 10 peer educators (schools and communities), interviews of 2 teenage street users, 3 teenage mosque interviews, 24 FGD participants (2 FGDs in School and 2 FGDs in the community). The results showed that the adolescent group of providers and users are still categorized as 'observers' (support, weak power, and passive involvement) in the implementation of the strategic steps of youth health programs. There are even teenagers from community youth groups who have not been exposed to teenage health programs. Adolescent health programs should involve teenagers from planning until evaluation. Therefore, the existing program suits needs and abilities of adolescents (from by for teenagers).
\end{abstract}

Keywords: adolescent, health, program

\section{Introduction}

Teenagers in Indonesia are very large, almost twenty-seven percent (26.9\%) of the population of Indonesia is classified as a teenage age group. According to the 2010 population census of Indonesia, shows that the age group is 30 percent of the population. The number of adolescents increased from 35 million in 1980 to more than 42.4 million in 2010 (BPS 2010; BPS 2004, 2007a; BPS 2007b). A large proportion can be used as an asset opportunity for the nation, but if the management is not optimal it will become a serious problem, especially health problems.

Today many of the risk behaviors cause health problems. The fact is the increasing number ofadolescents with HIV-AIDS, Sexually Transmitted Infections, unwanted pregnancy and drug abuse (Ministry of Health, 2016). According to data from BAPPENAS, UNFPA and BKKBN it is known that half of the 63 million people aged 10 to 24 years in Indonesia are vulnerable to unhealthy behavior. One of the most prominent among teenagers today is the issue of sexuality (pregnant out of wedlock, abortion, infected sexually transmitted diseases) as well as drug abuse (BKKBN, 2010). Meanwhile, from the results of several surveys from the Ministry of the Republic of Indonesia on research in 2014 it can be seen that adolescent knowledge about reproductive health is still low. Adolescents are faced with difficult times in development both mentally, socially, and culturally. This can be seen from the disharmony, emotional disturbance, and behavioral disorders as a result of the pressure experienced by adolescents. The existence of unconformity due to the 